\title{
RISCOS AMBIENTAIS EM AMBIENTE HOSPITALAR
}

ENVIRONMENTAL RISKS IN HOSPITAL

\author{
Wendel Mombaque dos Santos ${ }^{1}$, Cristiane Costa Schossler $^{2}$
}

\begin{abstract}
${ }^{1}$ Universidade Católica Dom Bosco, Pós Graduando em Ciências da Saúde pela Universidade Federal do Pampa e Mestrando da Universidade Federal do Pampa. Professor do Departamento de Enfermagem da Universidade Federal do Pampa.

${ }^{2}$ Professora do Curso de pós-graduação Lato Sensu da Universidade Católica Dom Bosco.
\end{abstract}

\begin{abstract}
RESUMO
O Hospital tem características de apresentar um elevado índice de riscos, aos quais os trabalhadores estão expostos com frequência no cotidiano de suas atividades. Esta pesquisa tem como objetivo identificar os riscos ambientais existentes na unidade de processamento de roupas de serviços de saúde. Trata-se de uma pesquisa exploratória de enfoque qualitativo e quantitativo em uma unidade de processamento de roupas de serviços de saúde, através de observação. O estudo possibilitou o conhecimento e a elaboração do mapa de riscos da unidade estudada, ficando evidenciada a grande quantidade de riscos a que estão expostos estes profissionais, que foi desenvolvido conforme a portaria $\mathrm{n}^{\circ} .25$ de 1994. A elaboração deste mapa de riscos contribuiu para os trabalhadores estarem cientes dos riscos a que estão expostos, de modo a adotarem medidas de proteção, com a utilização de equipamentos de proteção individual e coletiva.
\end{abstract}

Palavras-Chave: Enfermagem do trabalho; Riscos ambientais; Serviço hospitalar de lavanderia

\begin{abstract}
The Hospital has features to provide a high level of risk to which workers are exposed frequently in their everyday activities. Technological development, modern forms of organizations, and sophisticated management techniques can become an inexhaustible source of health problems. This research consisted of a case study in a processing unit clothing of health services. The study enabled the development of knowledge and risk map of the unit studied, being shown the large amount of risk they are exposed to these professionals. The preparation of this risk map contributed to workers being aware of the risks they are exposed in order to adopt protective measures, with the use of personal protective equipment and collective.
\end{abstract}

Keywords: Nursing labor; environmental risks; service, hospital laundry 


\section{INTRODUÇÃO}

O ambiente de trabalho é considerado como confuso e excessivo e inclui dimensões muito vastas com conotações econômicas, socioculturais e de segurança, inerentes ao ambiente humano (GRISI, 2000).

Uma maneira simples e inteligente de analisar o meio ambiente é a partir do local de trabalho. A cobrança de um meio saudável transcendeu aos alcances nacionais e constitui hoje, condição de peso ao comércio internacional (SEBRAE, 1998).

A história do homem é assinalada pela perfeita inter-relação com a natureza, da qual faz parte diretamente suas ações. O ambiente físico abrange tudo o que nos rodeia, e ainda, divide o ambiente físico em dois tipos: o construído ou modificado pelo homem e o natural. Já o ambiente hospitalar tem como finalidade a prestação de serviços de assistência com qualidade, eficiência e eficácia. Devendo ser garantida a redução de riscos e acidentes, proporcionando ambientes livres de riscos (HEIMSTRA, 1978; MULATINHO, 2001)

No hospital deve ser realizada a análise deles em todas as atividades de trabalho, sendo analisado e fundamentado em reconhecer, avaliar e controlar os riscos. (MULATINHO, 2001).

Os riscos ambientais incluem os agentes físicos, químicos, biológicos, ergonômicos e acidentais existentes nos ambientes de trabalho e que podem causar danos à saúde do trabalhador (CUNHA, 2005).A segurança no ambiente de trabalho é fundamental na qualidade de vida e trabalho dos colaboradores. $\mathrm{O}$ acontecimento de acidentes de trabalho é um fato indesejado pelas organizações que ocasiona perdas muitas vezes irreparáveis tanto para a organização como para com o trabalhador.

A Norma Regulamentadora NR-9 estabeleceu a obrigatoriedade de identificar os riscos à saúde humana no ambiente de trabalho atribuindo às Comissões Internas de Prevenção de Acidentes (CIPA) a responsabilidade pela elaboração de mapas de riscos ambientais. $\mathrm{Na}$ área de saúde, o controle dos riscos ambientais proporciona encontros com três áreas: a biossegurança, a saúde do trabalhador e a garantia de qualidade em estabelecimentos de saúde.

Considerando que no ambiente hospitalar a quantidade de riscos existentes é grande e exige cuidado redobrado, dentre os setores hospitalar destaca-se a lavanderia, pois é um dos serviços de apoio ao atendimento dos pacientes, responsável pelo 
processamento da roupa e sua distribuição em perfeitas condições de higiene e conservação, em quantidade adequada a todas às unidades do hospital. Desta forma este trabalho tem como objetivo identificar os riscos ambientais existentes na unidade de processamento de roupas de serviços de saúde e realizar o mapa de risco desta unidade.

Em meios do século XX, já vem se observando uma maior preocupação em relação ao meio ambiente e a interferência que pode ocasionar na saúde dos trabalhadores. Ao realizar a analise dos riscos ambientais estes trabalhadores poderão tomar medidas mais adequadas para que estes riscos interfiram o mínimo possível para a sua saúde, de modo que este estudo teve como objetivo verificar os riscos ambientais presentes em uma unidade de processamento de roupas de serviços de saúde em um hospital da fronteira oeste do Rio Grande do Sul.

\section{MATERIAIS E MÉTODOS}

Trata-se de uma pesquisa exploratória de enfoque qualitativo e quantitativo realizado na unidade de Processamento de Roupas de Serviços de Saúde de um hospital de referência do oeste do Rio Grande do Sul, Brasil.

A área física da unidade consiste de aproximadamente $450 \mathrm{~m}^{2}$, que atende 210 leitos sendo 165 vinculados ao sistema único de saúde, gerando um processo de 1 mil quilos de roupas processadas diariamente.

Os dados foram coletados em duas etapas, no mês de setembro de 2012, sendo: a primeira etapa constituída da observação de campo não participante da estrutura física para a realização da verificação dos riscos, funcionamento do serviço e medidas para a redução dos riscos observáveis.

A segunda etapa realizou o levantamento de dados no Serviço Especializado em Saúde e Medicina do Trabalhador, através de instrumentos utilização para notificação de acidentes, para caracterizar os acidentes dos trabalhadores do referido serviço.

Foram respeitados todos os aspectos éticos conforme a resolução 466/2012 e por se tratar de uma pesquisa com fonte de dados secundárias de acesso público (notificações de acidentes) e avaliação do ambiente físico (verificação dos riscos ambientais) não houve necessidade de apreciação da pesquisa por Comitê de Ética em Pesquisa, por não envolver os trabalhadores na pesquisa. 


\section{RESULTADOS}

Foram verificados riscos físicos, químicos, ergonômicos, de acidente e biológico na unidade verificada. A seguir será apresentada uma tabela esquemática da unidade de processamento de roupas do local de estudo, demonstrando seus principais riscos.

\section{Figura 1 - Mapa de Riscos da Lavanderia}

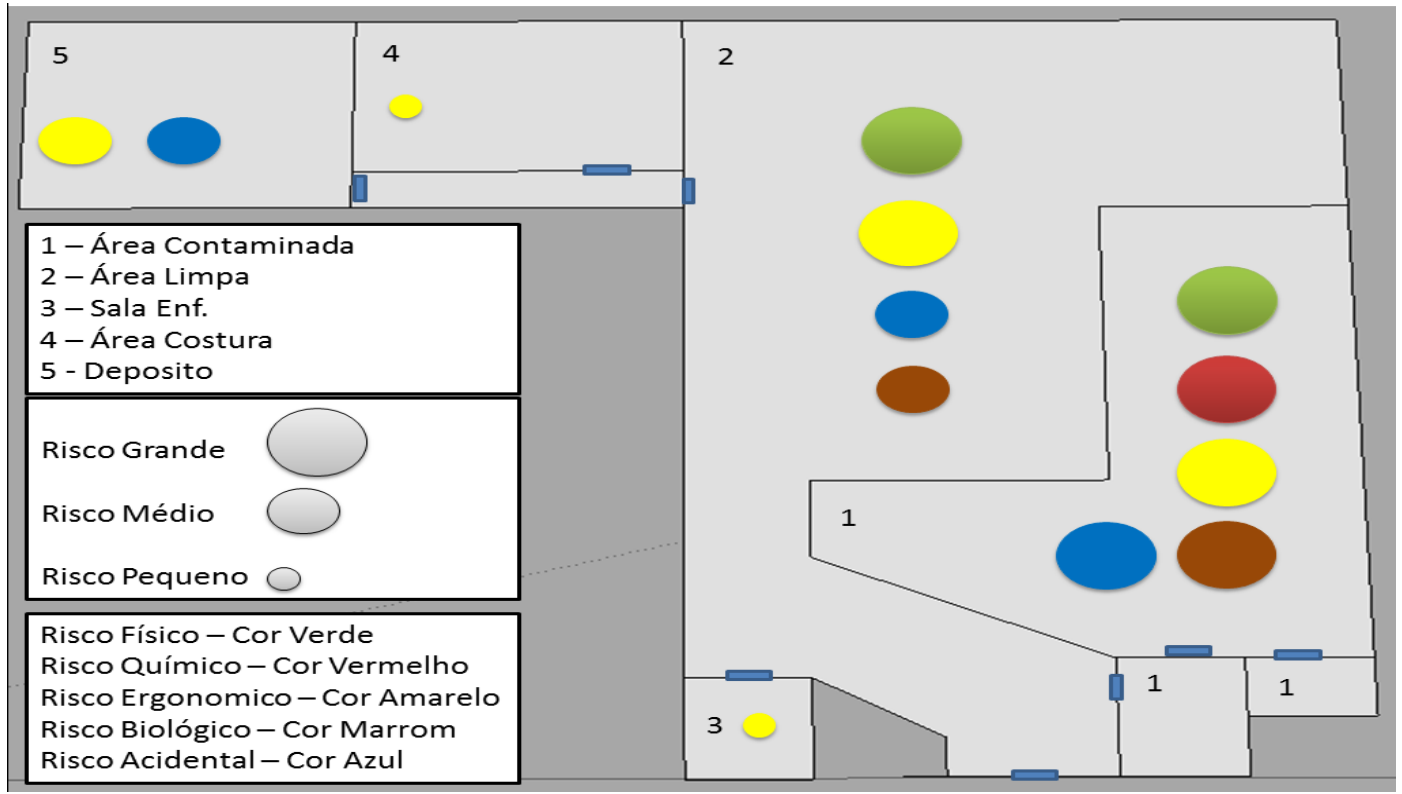

Fonte: Pesquisadores, 2012.

A área contaminada apresenta risco físico grande pelas altas temperaturas provenientes do vapor que é utilizado para aquecer a água durante o processo de lavagem. Na avaliação de temperatura ambiente, os valores apresentados ficaram de 35.0 oC a 40.0 o $\mathrm{C}$, em desacordo com a NR no 17, devendo ser necessária a implantação de medidas que se tornem o ambiente mais propicio para o trabalho.

Assim, como o risco químico, que é grande pelo fato de todos os produtos químicos utilizados no processo de lavagem estão presentes no local, tendo o funcionário ter de realizar a troca dos mesmos no próprio ambiente de lavagem de roupas, de modo que ao haver o derramamento de algum liquido que produza gás tóxico este irá demorar para se dissipar devido a limitação de exaustão do local.

O risco ergonômico é grande visto que o funcionário permanece a maioria do tempo em pé e executa diversos movimentos inadequados, como quando coloca a roupa 


\section{Ensino, Saúde e Ambiente - V6 (3), pp. 39-52, dez. 2013}

na lavadora de roupas. Fato este que fica evidente devido a $50 \%$ dos funcionários deste setor já terem apresentado problemas de saúde em decorrência da atividade laboral.

O risco biológico é grande pelo fato de todas as roupas do hospital irem ao setor e estas apresentarem restos que fluidos corporais. O risco acidental é grande devido a grande quantidade de maquinas, que se utilizadas inadequadamente oferecem grandes riscos de acidente, assim como acidente com materiais perfurantes e cortantes que algumas vezes estão junto com as roupas. Entretanto não houve acidentes no período de 1 ano com material biológico, mas é frequente (média de 2 materiais perfurantes e cortantes por semana) o aparecimento de materiais perfurante e cortantes na roupa.

A área limpa apresenta físico grande pelas altas temperaturas provenientes do vapor que é utilizado para aquecer a calandra e as secadoras. $\mathrm{Na}$ avaliação de temperatura ambiente, os valores apresentados ficaram de 34.0 oC a 41.0 o C, em desacordo com a NR no 17, devendo ser necessária a implantação de medidas que se tornem o ambiente mais propicio para o trabalho.

O risco ergonômico é elevado, visto que o funcionário permanece todo tempo em pé e executa diversos movimentos inadequados, como retirar a roupa molhada da lavadora e colocar na secadora de roupas. Fato este que fica evidente devido a $75 \%$ dos funcionários deste setor já terem apresentado problemas de saúde em decorrência da atividade laboral.

O risco biológico é médio pelo fato de algumas as roupas saírem do processo de lavagem com algum resto pequeno de fluidos corporais. Entretanto não houve nenhum acidente com material perfurante e cortante na área limpa.

O risco acidental é grande devido a grande quantidade de maquinas, que se utilizadas inadequadamente oferecem grandes riscos de acidente, assim como acidente com materiais perfurantes e cortantes que algumas vezes estão junto com as roupas. Sendo registrado um acidente por um funcionário ter tomado um choque ao manusear uma maquina, ficando evidente a falta de manutenção adequada das maquinas.

A área de costura apresenta risco ergonômico pelo fato de permanecer muito tempo sentado na mesma posição.

O deposito apresenta risco ergonômico e acidentam médio por ser utilizado uma escada para pegar as roupas que ficam em locais mais altos, fator este que muitas vezes prejudica a postura do trabalhador e pela escada ser inadequada oferece risco de queda. 
A área do enfermeiro coordenador da lavanderia apresenta risco ergonômico pequeno pelo fato de permanecer muito tempo sentado na mesma posição.

\section{DISCUSSÃO}

A preocupação com a segurança e saúde do trabalhador vem sendo registrada desde o século IV a.C., quando Aristóteles (384 - 322 a.C.) cuidou do atendimento e prevenção das enfermidades dos trabalhadores. Plínio publicou a "História Natural", na qual foram tratados temas alusivos à Segurança do Trabalho, ponderando sobre o chumbo, mercúrio e poeiras e cita o uso de máscaras pelos operários dessas atividades. Hipócrates (460 - 370 a.C.) revelou a origem das doenças profissionais que acometiam os trabalhadores nas minas de estanho (HEIMSTRA, 1978). Demonstrando que aspectos relacionados a qualidade de vida do trabalhador são estudados a muito tempo, entretanto agora que tem despertado uma atenção maior dos pesquisadores, principalmente em ambiente hospitalar.

Originado do Tratado de Versalhes, em 1919, foi criada a Organização Internacional do Trabalho (OIT) que substituiu a Associação Internacional de Proteção Legal ao Trabalhador (BRASIL 1995). E no Brasil somente em 1978, com a Portaria ${ }^{\circ}$. 3.214, é criada as Normas Regulamentadoras e a partir de 1994, com a Portaria $n^{\circ} .25$, de 29 de dezembro, é instituído o Mapa de Riscos e Programa de Prevenção de Riscos Ambientais, demonstrando assim a recente implantação destes mapas de risco em instituições (SEGURANÇA E MEDICINA DO TRABALHO, 2000). Diversas instituições não tem implementado a utilização do Mapa de Riscos, tal como no Hospital pesquisado, demonstrando a fragilidade e atual omissão com aspectos relacionados a saúde do trabalhador.

A saúde está fortemente pautada com o desenvolvimento, devendo dar especial apoio e atenção aos programas preventivos que não se atenham apenas a remediar e tratar doenças. O hospital tem como fim a prestação de serviços de assistência com qualidade, eficiência e eficácia (BARBIERI, 1998). Está qualidade da assistência não deve ser restrita somente aos clientes da instituição, mas aos trabalhadores através de um Sistema de Gestão efetivo, de um programa de prevenção de acidentes que proporcione um ambiente seguro e adequado a estes trabalhadores. 


\section{Ensino, Saúde e Ambiente - V6 (3), pp. 39-52, dez. 2013}

No Hospital, deve ser garantida a redução de riscos e acidentes. Para isso devese solicitar e reforçar práticas seguras de trabalho e proporcionar ambientes livres de riscos, observando-se a legislação vigente municipal, estadual e federal. Além das preocupações legais em definir os riscos existentes no ambiente hospitalar, é importante inventariá-los de forma objetiva e racional.

O risco aponta uma probabilidade de possíveis danos dentro de um período de tempo ou ainda pode significar a incerteza quanto à ocorrência de um determinado evento. No hospital, encontra-se vários riscos, devendo, no entanto, ser realizada a análise deles em todas as atividades de trabalho (VIANA, 2010). Salientando-se assim a importância dos trabalhadores conhecerem os riscos há que estão expostos, de forma a adotarem medidas mais eficientes e eficazes para a eliminação ou minimização destes.

Visando à eliminação e/ou controle dos riscos, eles devem ser analisados e fundamentados nos seguintes conceitos:

- Reconhecer: identificar, caracterizar, saber apontar qual dos agentes de riscos, de dano à saúde estão presentes no ambiente de trabalho;

- Avaliar: saber verificar, de acordo com determinadas técnicas, a magnitude do risco. Se for grande, médio ou pequeno, comparado com determinados padrões;

- Controlar: é adotar medidas técnicas, administrativas, preventivas ou corretivas de diversas naturezas, que tendem a eliminar ou atenuar os riscos existentes no ambiente de trabalho.

Cabe aos administradores e supervisores a responsabilidade de zelar para que tanto o ambiente quanto os funcionários apresentem-se em condições adequadas de segurança, e cabe a cada um deles seguir as práticas de segurança no trabalho e controle de prevenção das doenças como parte rotineira e normal de suas atividades.

\section{Riscos Físicos no Ambiente Hospitalar}

Encontramos, no ambiente hospitalar, agentes físicos entre os quais: calor, ruído, radiações ionizantes e não-ionizantes, pressões anormais e umidade. O calor é uma forma de energia determinada pela variação de temperatura do corpo que cedeu ou recebeu calor. A transmissão por radiação é feita através de ondas eletromagnéticas que se transmitem através do ar e do vácuo (VIANA, 2010). Sendo a lavanderia hospitalar um dos locais que apresentam a maior quantidade de riscos físicos em seu ambiente, principalmente por apresentarem equipamentos antigos e sem manutenção adequada. 
O calor em quantidade elevada pode causar efeitos indesejáveis sobre o corpo humano, como: golpes de calor (insolação), cujos sintomas são: colapso, convulsão, delírio, alucinações entre outros; desidratação ou queda do teor da água, caracterizada pelo aumento da pulsação e da temperatura do corpo; queda do teor de sal, ocorrendo fadiga, tontura, náuseas, vômitos e cãibras musculares (VIANA, 2010). Ao passo que desde o processo de lavagem são utilizados elevados padrões de temperatura $\left(60^{\circ} \mathrm{C}\right) \mathrm{e}$ durante todo o processo de secagem e calandragem da roupa, estes trabalhadores devem manter especial atenção ao padrões adequados de temperatura ambiente, assim como dos equipamentos.

A umidade excessiva deve ser observada e prontamente corrigida, no Hospital visto que a lavandeira é o local onde se faz mais uso de água dentro do ambiente hospitalar. Em outros ambientes a umidade pode ser detectada por, inspeção visual através de manchas nas paredes e pisos, decorrentes de infiltrações de água, por danos na tubulação ou mesmo de esgotos. Danos de maiores consequências podem ocorrer, acarretando até a desestruturação do prédio (BRASIL, 1995). De forma que os trabalhadores e a equipe de manutenção deve estar atenta a estes fatores, visto que um ambiente aonde a umidade é elevada dificulta a transpiração dos funcionários, podendo levar a alterações no sistema físiológico destes e acarretar agravos a saúde dos trabalhadores.

O controle da umidade deve ser observado desde o projeto inicial de edificação. O uso de placas de advertência é outra medida a qual se utiliza para evitar acidentes (VIANA, 2010).

As radiações ionizantes no ambiente hospitalar são aquelas nas áreas de radiodiagnóstico e radioterapia ou em áreas que utilizem os equipamentos de diagnóstico como centros cirúrgicos e unidades de terapia intensiva. Embora seus efeitos variem de pessoa para pessoa, a exposição prolongada pode encurtar a expectativa de vida.

As radiações não-ionizantes no ambiente hospitalar apresentam-se nos processos que fazem uso da luz ultravioleta, a luz infravermelha, empregada na fisioterapia, e em procedimentos cirúrgicos na forma de laser. Ambos podem produzir queimaduras.

As vibrações, de acordo com o Anexo 8 da NR 15 da Portaria 3214/78 Segurança e medicina do trabalho, MT (2000), diz "as atividades e operações que exponham os trabalhadores, sem a proteção adequada, às vibrações localizadas ou de 
corpo inteiro, serão caracterizadas como insalubres, através de perícia realizada no local de trabalho". Os efeitos danosos das vibrações podem acometer pessoas, as estruturas da edificação e os equipamentos sensíveis, cujo efeito das vibrações impedem o seu funcionamento adequado. No corpo humano, causam, entre outros sintomas, cansaço, dores nos membros, dores na coluna, artrite, problemas digestivos, lesões ósseas, lesões dos tecidos moles e lesões circulatórias.

No ruído a ocorrência de perda auditiva depende da intensidade (nível da pressão sonora), do tipo (continuo, intermitente ou de impacto), da duração (tempo de exposição a cada tipo de agente) e da qualidade (freqüência dos sons que compõe o ruído em análise). O organismo pode desencadear sérias perturbações, afetando o sistema nervoso, os aparelhos digestivo e circulatório, traz desconforto e fadiga, influindo em sua produtividade profissional (VIANA, 2010).

A avaliação do risco legalmente deverá ser feita através da análise do ambiente de trabalho, visando determinar os períodos de descanso a que o trabalhador tem direito, segundo os tipos de trabalho realizado.

\section{Riscos Químicos no Ambiente Hospitalar}

Os trabalhadores de saúde estão expostos à enorme variedade de substâncias tóxicas. Nos hospitais, são utilizados em grandes quantidades os produtos químicos com diversas finalidades: metais - intoxicação por chumbo, mercúrio, manganês, cádmio etc.; gases e vapores - intoxicação por monóxido de carbono etc.; agentes de limpeza, desinfecção, esterilização, como produtos de manutenção de equipamentos e instalações, e largamente utilizados como soluções medicamentosas. A circulação desses produtos no ambiente hospitalar, tanto em embalagem original como em preparações para uso, deve ser tal que garanta a proteção de quem os transporta e evite a contaminação do ambiente (VIANA, 2010).

Os riscos químicos são encontrados nos processos químicos de esterilização usados abundantemente nos hospitais, podendo-se fazer uso de gases ou líquidos, ambos prejudiciais à saúde.

Os produtos quimioterápicos são ministrados nos tratamentos de pacientes com o objetivo de reduzir tumores malignos (células cancerígenas). As drogas bacteriostáticas (que detêm o crescimento dos germes) são denominadas de citostáticos, pois impedem o crescimento das células. 


\section{Ensino, Saúde e Ambiente - V6 (3), pp. 39-52, dez. 2013}

No armazenamento, estocagem, transporte, manipulação e aplicação desses produtos, dever-se-á observar todas as medidas preventivas, assim como treinamento adequado do pessoal que faz o manuseio. A aplicação inadequada dessas substâncias pode trazer sérias consequências aos pacientes e funcionários que executam esse tipo de serviço. Pode significar a diferença entre saúde e doença, e, em casos extremos, entre a vida e a morte.

O reconhecimento dos riscos deve ser feito de acordo com a característica de cada instituição hospitalar. Esta deve possuir a ficha de cada produto que entra no hospital, desse modo, todos os produtos químicos e seus riscos podem ser conhecidos pelos profissionais, permitindo que sejam tomadas medidas de controle, as quais visam educar e treinar o trabalhador para as atividades necessárias ao serviço. Tais medidas envolvem a proteção do trabalhador através do uso de Equipamentos de Proteção Individual (EPI), controle a saúde através de exames médicos periódicos e a limitação do tempo de exposição do trabalhador à fonte de risco (VIANA, 2010).

Algumas medidas tomadas em relação ao ambiente de trabalho são: a substituição do produto tóxico ou nocivo, a mudança do processo ou o encerramento da operação e manutenção das medidas de controle adotadas.

\section{Riscos Biológicos no Ambiente Hospitalar}

O risco biológico é intensivamente encontrado no ambiente hospitalar, pois este reúne densa população microbiológica, infecções cruzadas, contato com sangue e outros fluidos corporais, manipulação de amostras patológicas, deficiência de higiene e de limpeza na lavagem das mãos, falha nos processos de desinfecção, esterilização e assepsia (VIANA, 2010).

Os riscos biológicos abrangem doenças transmissíveis agudas e crônicas, parasitoses, reações tóxicas e alérgicas a plantas e animais. Esse risco é representado para os trabalhadores de saúde principalmente pelas infecções causadas por bactérias, vírus, richettsias, clamídia e fungos (VIANA, 2010).

$\mathrm{Na}$ maioria das vezes, devido ao contato que os profissionais têm com o paciente infectado, o próprio rosto (conjuntiva ocular, mucosas da boca e do nariz) ao alcance do ar por eles expirado, ao contato com os respingos de sangue e outros fluidos corporais, quando de procedimentos invasivos, vômitos, tosses, espirros, entre outros. 


\section{Ensino, Saúde e Ambiente - V6 (3), pp. 39-52, dez. 2013}

As maiores fontes de contaminação são através do contato mão-boca, o contato mão-olho, os cortes e feridas superficiais na pele exposta e perfuração cutânea (BRASIL, 1995).

Os edifícios hospitalares também estão doentes, encontramos infestação de ratos, baratas, formigas, moscas, pombos e até gatos que hospedam e transportam germes e doenças, além disso, os aspiradores, nebulizadores, pias, bicas de torneiras, limpezas mal feitas, vasos de plantas e flores.

Os profissionais da área devem ter plena consciência da segurança em seu ambiente de trabalho. Normalmente, por não terem sido infectados, alguns profissionais acham que o seu ambiente de trabalho é inócuo. A implementação de novas técnicas de segurança devem ser buscadas e adotadas sempre que as medidas utilizadas na instituição se mostrarem ineficazes (VIANA, 2010).

\section{Riscos Ergonômicos no Ambiente Hospitalar}

Observam-se as psiconeuroses e outras manifestações de ordem emocional, movimentos repetitivos - tenosinovite -, ou na tentativa de posicionar ou Movimentar o paciente, ocasionando sérios problemas relativos à coluna vertebral.

A ergonomia visa à adaptação do meio ambiente do trabalho ao homem. Estudos antropométricos e posturais, baseiam-se na análise da atividade decorrente a carga de trabalhos físico, mental e psíquico, gerada pela excessiva atividade laboral.

As condições de trabalho incluem aspectos relacionados com o levantamento, transporte e descarga de materiais, o mobiliário, os equipamentos, a própria organização do trabalho, imposição de ritmos excessivos, jornadas de trabalho prolongadas, trabalho noturno, monotonia, repetitividade e outras situações causadoras de estresse físico e/ou psíquico etc.

A NR-17, que trata das questões de Ergonomia, deve ser aplicada em todas as atividades profissionais e respectivos ambientes de trabalho. Deve-se observar o seguinte: "o mobiliário para o trabalho executado seja na posição em pé seja sentado deve ser planejado e adaptado às posições requeridas; os equipamentos que compõem o posto de trabalho devem estar adequados às características dos trabalhadores e ao trabalho; as condições ambientais devem observar o conforto térmico, o nível de ruído nos seus limites e todos os parâmetros de iluminação e visualização segura e eficiente para as atividades; a organização do trabalho deve levar em consideração: normas de 


\section{Ensino, Saúde e Ambiente - V6 (3), pp. 39-52, dez. 2013}

produção, o modo operatório, a exigência do tempo, a determinação do conteúdo de tempo, o ritmo de trabalho e o conteúdo das tarefas. Esses aspectos devem estar adequados às características psicofisiológicas dos trabalhadores e à natureza de trabalho executado" (SALAROLI,1999)

\section{Riscos de Acidentes no Ambiente Hospitalar}

Os riscos de acidentes ocorrem com funcionários durante o seu trabalho devido a vibrações, doença arterial periférica, máquina e equipamentos sem proteção, probabilidade de incêndio e explosão, eletricidade, iluminação inadequada ou toda situação de risco que poderá gerar acidentes.

Nos pacientes, verificamos diversas causas, como: (escorregões e quedas durante a deambulação, banho, movimentação em macas etc.). Nos EUA, 10\% das ações legais que representaram custos para os hospitais, durante um período de três anos (1975 a 1978), envolveram quedas. Outro estudo mostrou que, de 875 reivindicações, $20 \%$ foram devidas a quedas e escorregões (Brasil, MS, 1995).

A iluminação adequada propicia índice elevado de produtividade, melhor condução dos processos de trabalho, melhor qualidade do produto final, redução do número de acidentes. No ambiente hospitalar, deve ser enfocada nas salas de cirurgias e campos operatórios, contribuindo, assim, para a redução de acidentes. Muito comuns são os acidentes com materiais perfurocortantes ou cortocontusos (contaminados), encontrados depositados em recipientes inadequados, assim como a não-utilização de equipamentos de proteção individual (EPIs), os quais podem levar a um risco do tipo biológico. Dessa forma, a coleta de lixo hospitalar deve ser seletiva, definindo-se quais os recipientes que devem ser utilizados para a coleta dos resíduos.

A prevenção desses riscos visa a busca de ambiente físico propício à eficácia, ao conforto, à segurança e satisfação do trabalhador através do uso de regras, normas e regulamentos de um sistema de gestão de segurança e saúde do trabalho.

\section{CONSIDERAÇÕES FINAIS}

O enfermeiro do trabalho tem papel fundamento no Serviço Especializado em Engenharia de Segurança e Medicina do Trabalho, devido a seus conhecimentos dos riscos existentes no local de trabalho e suas possíveis consequências para a saúde destes 
trabalhadores, a correta orientação do enfermeiro do trabalho de modo a conscientizar e treiná-los tem fundamental importância para a instituição e seus trabalhadores.

Os dados apresentados demonstram como os ricos de acidentes em um ambiente de lavanderia hospitalar são elevados e para o conhecimento e realização do mesmo foi criado o mapa de risco que foi entregue ao setor para poder contribuir para a capacitação cotidiana dos profissionais.

Deste modo a elaboração do mapa de risco facilita a melhor visualização dos fatores de risco de um determinado local, possibilitando um maior conhecimento destes riscos existentes no ambiente e uma melhor ação para medidas de controle. Neste estudo foi realizado o mapeamento no setor de lavanderia de um hospital da região oeste do Rio Grande do Sul, no qual ficou evidencia que a unidade estudada apresenta inúmeros riscos ambientais que se não forem utilizados os equipamentos de proteção individual e coletiva, poderá colocar em risco a saúde destes trabalhadores. Portanto esperamos que através deste estudo seja possível a implementação de novas medidas de controle e minimização da exposição destes fatores aos funcionários.

Ainda vale ressaltar a importância da realização de mapa de riscos ambientais em todos os setores do hospital, de modo a assegurar o conhecimento e medidas preventivas a estes riscos.

\section{REFERÊNCIAS}

BARBIERI, José Carlos. Desenvolvimento e meio ambiente: as estratégias de mudanças da Agenda 21. Petrópolis: Vozes, 1997, p.37, 135.

BRASIL, Ministério da Saúde. Segurança no ambiente hospitalar. Departamento de Normas e Técnicas . Brasília: 1995, 193p.

BRASIL, Ministério da Saúde. Segurança no ambiente hospitalar. Departamento de Normas e Técnicas . Brasília: 1995, 193p

BRASIL. Norma Regulamentadora 9. Brasilia, 1994.

CHIAVENATO, Idalberto. Higiene e segurança do trabalho. In: Recursos humanos. São Paulo, cap.V, p.441- 447, 4.ed. Atlas, 1997.

CHIAVENATO. Iniciação à administração de pessoal. São Paulo: Makron Book, 1994,p.

CUNHA, Renata Carvalho Murad Leal da. (Coord.). Manual Sobre Programa de Riscos. Plural Art, 1999, p.45,46. 
GIL, M.B. Estresse dos trabalhadores de enfermagem: estudo em uma unidade de psiquiatria. 1999. Dissertação (Mestrado em Enfermagem). Faculdade de enfermagem - UFRJ, Rio de Janeiro, 1999.

GRISI, Breno Machado. Glossário de ecologia e ciências ambientais. 2.ed. João Pessoa: UFPB, 2000, p.121.

HEIMSTRA, Norman W; McFARLING Leslie H. Psicologia ambiental. São Paulo: EPU, 1978, p.1-7.

MAANEN, J.V. Reclaiming qualitatives methods for organizathional research: a preface. Administrative Science Quarterly, v. 24, n. 4, p. 520-526, 1979.

MANUAIS DE LEGISLAÇÃO ATLAS. Segurança e medicina do trabalho. 47.ed. São Paulo: Atlas, 2000, 665p.

MULATINHO, Letícia Moura. Análise do sistema de gestão em segurança e saúde no ambiente de trabalho em uma instituição hospitalar. João Pessoa:2001.

NEVES, J.L. Pesquisa Qualitativa: Caracteristicas, usos e possibilidades. Caderno de Pesquisa em Administração. São Paulo, v. 1, n. 3, 1996

SALAROLI. Carlos Alberto. Cartilha do trabalhador. Lesões por Esforços Repetitivos/ Distúrbios Ósteomusculares relacionados ao Trabalho. São Paulo: 1999. SERVIÇO BRASILEIRO DE APOIO AS MICRO E PEQUENAS EMPRESAS SEBRAE. A questão ambiental e as empresas. 3. ed. Brasília: 1998, p.39, 40 e 84) THEODORSON, G. A.; THEODORSON, A. G. A modern dictionary of sociology. London, Methuen, 1970.

VALENTIM, M.L.P. (Org.). Métodos qualitativos de pesquisa em Ciência da Informação. São Paulo: Polis, 2005.

VIANA, D.B. avaliação de riscos ambientais em áreas contaminadas: uma proposta metodológica. Rio de Janeiro, 2010. 